\title{
Flume Experiments on Scour Downstream of Wood Stream Restoration Structures
}

\author{
Stefano Pagliara ${ }^{\mathrm{a}, *}$, Sahameddin Mahmoudi Kurdistani ${ }^{\mathrm{b}}$ \\ ${ }^{a}$ Department of Energy, Systems, Territory and Construction Engineering (DESTEC), University of Pisa, Via Gabba 22, Pisa \\ 56122, Italy \\ ${ }^{b}$ Department of Engineering for Innovation, University of Salento, Ecotekne, Corpo O, Lecce 73100, Italy
}

\begin{abstract}
:
River restoration aims to improve physical natural form and processes of a river. Techniques to control the riverbed, stabilize channel alignment, protect stream banks and rebuild the natural habitat are an important part of river restoration projects. Rivers can be stabilized and habitat restored through techniques such as rebuilding meanders and pool-riffle sequences and managing large wood. Structures that limit channel width to accelerate the normal flows through the constricted section are referred to as stream deflectors. Single-wing, double-wing and triangular deflectors are the most commonly used types of this measure. Log-Frame deflectors consist of a triangular log frame filled with rock. Deflector constructions singly or in series in low gradient meandering streams, divert base flows towards the center of the channel and, under certain conditions, increase the depth and velocity of flow thereby creating scour pools and enhancing fish habitat. Scour characteristics and morphologies downstream of Log-Frame Deflectors have been analyzed at the hydraulic laboratory of the University of Pisa. All experiments have been carried out in clear water condition. The results showed that the tailwater depth plays an important role on scour characteristics. In addition, it was experimentally proven that using Log-Frame Deflectors instead of Log-Deflectors result in a better river bank protection. In this case, for all the tested hydraulic conditions, the scour hole never occurred close to the channel bank. Useful empirical relationships have been proposed in order to evaluate the main features of the scour geometry.
\end{abstract}

Keywords: Morphology; Stream Restoration; Eco-Friendly In-stream Structures, Hydraulic Structures; Grade-control Structures; GCSs; Log-Deflector; Log-Frame Deflector; Scour

\footnotetext{
${ }^{*}$ Corresponding author. Tel.: +39 (050) 2217717

E-mail addresses: s.pagliara@ing.unipi.it (S. Pagliara), s.m.kurdistani@unisalento.it (S.M. Kurdistani)
} 


\section{Introduction:}

Leopold (1994) described the river channels similarity, regardless of size, overshadows differences among rivers in various climates and geological settings. River rehabilitation can be passive, where we simply allow natural hydraulic forces to reshape rivers slowly and reinstate the natural heterogeneity (Gillilan et al. 2005). Woody stream restoration structures stabilize the riverbed and protect the river bank. Natural channel design approach (Rosgen 2001) is the most commonly river restoration activities accomplished by restoring the dimension, pattern, and profile of a disturbed river system by emulating the natural, stable river. Woody stream restoration structures like Log-Deflectors and Log-Frame Deflectors as In-stream grade control structures are used to stabilize riverbed, riverbanks, and improving aquatic habitat in the rivers. Scour hole works like a resting pool for fish and helps fish to rest and then migrate upstream for spawning. Also in the case that scour hole occurs towards the center of the channel and ridge develops towards the riverbank, means that we are stabilizing the riverbed and protecting the riverbank especially at the river bends.

In the scientific literature, there are no comprehensive studies on scour downstream of woody stream structures. Jansen et al. (1979), Odgaard and Spoljaric (1986), Odgaard and Mosconi (1987) and Odgaard and Wang (1991) gave major contributions on submerged vanes hydraulic. In the literature, few experimental contributions, focused on grade-control structures, can be found. Przedwojski (1995) showed the effect of the groyne location on the depth of local scour. Simon and Darby (2002) conducted a morphological analysis on the effectiveness of grade-control structures (GCSs) in reducing erosion along $18 \mathrm{Km}$ length of Hotophia Creek, Mississippi. They found that GCSs installed along Hotophia Creek, for the most part, have been ineffective in reducing channel erosion rates. They showed that this is because the GCSs were installed too late to prevent bed degradation, caused by the 1961-1963 channelization, migrating upstream. Lenzi and Comiti (2003) studied on local scouring and morphological adjustments in steep channels with check-dam sequences. Local scouring characteristics (maximum depth and length) downstream of 29 drop structures in a steep mountain river were analysed and compared to flume data obtained by experiments in the same non-uniform sediment mixture appropriately scaled. They showed that drop height, flow depth, and step spacing affect scouring dynamics. Roca et al. $(2007,2009)$ showed that a horizontal foundation of the outer river bend, could protect vertical outer banks against erosion reducing the scour depth. Bhuiyan et al. (2007) studied the scour morphology downstream of W-weir at river bends in both clear water and live-bed conditions. Bhuiyan et al. (2010) showed that multiple vanes angled at $30^{\circ}$ to the bank line effectively relocate the deeper channel away from the outer bank in a bend. 
Tian Zhou and Ted Endreny (2011) showed that J-hook geometry and placement within natural meanders could be analyzed with CFD models (Computational Fluid Dynamics) to help restoration teams reach design goals and understand hydraulic impacts. Khosronejad et al. (2013) conducted an experimental and numerical study on local scour around three different rock grade-control structures including a rock weir, a cross vane, and a J-Hook vane in clear water condition. Khosronejad et al. (2014a) extended the coupled hydro-morphodynamics VLS3D model of Khosronejad et al. (2013) to simulate flow and sediment transport with arbitrarily complex rock structures in natural meandering streams under live-bed conditions. Khosronejad et al. (2014b) used VLS3D model with both URANS (Unsteady Reynolds-averaged Navier-Stokes) and LES (Large Eddy Simulation) approaches to simulate turbulent flow in different open channels, ranging from a stream to rivers, under live-bed conditions in the presence of different in-stream rock structures.

Scurlock et al. (2012a) experimentally studied velocity distribution around the vane-dike in channel bends. Scurlock et al. (2012b) carried out an experimental study on scour downstream of Cross-Vane and $\mathrm{W}$-weirs in straight channels to estimate the maximum scour depth. Pagliara and Kurdistani (2013) carried out an experimental study on scour downstream of Cross-Vane structures in a sloped straight channel and derived equations to estimate the main scour parameters. They defined $\eta=$ $\mathrm{F}_{d}^{2} \cdot \Delta y / h_{s t}$ as scour parameter which is used in the current study to classify the scour morphology downstream of woody stream restoration structures. $F_{d}$ is densimetric Froude number, $\Delta y$ is the water level difference between upstream and downstream of the structure and $h_{s t}$ is the height of the structure. Pagliara et al. (2013, 2014a) investigated the scour morphology in straight rivers downstream of J-Hook vane and W-weir respectively. Pagliara and Kurdistani (2014) compared scour hole characteristics downstream of Cross-Vane and W-weirs, highlighting similitudes and differences in the respective ranges of application. Pagliara et al. (2014b, 2015) studied on the scour morphology in straight rivers downstream of Log-Vane and Log-Deflector structures respectively. Kurdistani and Pagliara (2015) studied on the installation angle effects for woody structures and found that in case of Log-Vanes there is no scour hole close to the channel bank. On the other hand, installing LogDeflectors needs special consideration to avoid the occurrence of scour holes close to the channel bank. Pagliara and Kurdistani (2015) showed the effect of the channel curvature on the main scour parameters values and scour morphology downstream of J-Hook vanes. They showed that increasing the bend radius, decreases the values of all scour parameters. Pagliara et al. (2016) carried out a series of experiments on scour downstream of sills in the straight and curved channels.

Jamieson et al. (2013a) studied on the stream barbs how redirect the high velocity core from the outer bank and prevent erosion of the flood plain at the bend exit. They showed as barbs size and layout generates excessive secondary velocities that are opposing the primary secondary flow naturally 
occurring in channel bends, the outer bank may still be at risk of erosion or even increase erosion. Jamieson et al. (2013b) experimentally studied on turbulence and vorticity in a channel bend in clearwater condition in the presence and absence of stream barbs and they showed that local scour near the barbs was associated with increased z-vorticity.

Melville (1992) derived simple equations to predict the maximum scour depth for local scour at bridge abutments. Based on Melville's study, Kuhnle et al. (1999) carried out a series of experiments on local scour associated with $90^{\circ}$ spur dikes. Kuhnle et al. (2002) conducted another series of experiments on local scour associated with angled non-submerged spur dikes. Melville (2014) presented a new equation based on Shields critical velocity to predict scour downstream of submerged weirs. Guan et al. (2014a) conducted a series of experiments to investigate the flow turbulence in a submerged weir scour hole. They showed that along the flume centerline longitudinal direction, a recirculation zone and a flow reattachment region were developed. The turbulence structures at the upstream end of the recirculation zone govern the dimensions of the scour hole. Recently Guan et al. (2014b) studied live-bed scour at submerged weirs. Finally, Galia et al. (2015) studied the effect of grade-control structures at various stage of their destruction on bed sediment and local channel parameters.

The main purpose of this study is to experimentally analyze the scour morphology downstream of woody stream restoration structures, namely Log-Deflectors and Log-Frame Deflectors in the straight channels to find the differences and similarities. It is important to precisely know, how the scour morphology around these type of structures varies for different hydraulic conditions to enforce designers to select the best structure configuration to protect the river bank and stabilize the riverbed. Pagliara et al (2015) conducted 54 experiments on Log-Deflectors and presented some empirical equations to predict the main scour parameters. Dimensionless tailwater ratio was considered as a parameter for the calculation of the maximum scour depth. For the other parameters such as maximum scour length, the maximum ridge height and the maximum ridge length further tests were needed. Therefore, another important purpose of this study is to improve previous obtained equations introducing in a more explicit way the tailwater as parameter. According to Pagliara et al. (2015), two different scour morphologies downstream of woody stream restoration structures have been defined for straight rivers. They introduced morphology Type C, where just one scour hole occurs at the end of each deflector and develops towards the center of the channel (Fig. 1a, b). In morphology Type D two scour holes develop wich one scour hole occurs at the end of the deflector $\left(z_{1 m}\right)$ and another one occurs close to the channel bank $\left(z_{2 m}\right)$ which is shown in Fig. 1c, d. Obviously the last goal of this study is to discuss about the effect of the geometry of the Log-Frame Deflector on defined types of the scour morphology. 


\section{Laboratory Facilities and Methods}

\subsection{Experimental Apparatus}

All 17 experiments were carried out in a straight horizontal channel $0.5 \mathrm{~m}$ wide, $15 \mathrm{~m}$ long and 0.5 m high (see Fig. 2a, b) made at the Hydraulic Laboratory of the University of Pisa. An overhead tank supplied stable inflow. The discharge was measured with precision of $\pm 0.1 \mathrm{l} / \mathrm{s}$ using a magnetic current meter. A point gauge of reading accuracy of $\pm 0.0001 \mathrm{~m}$ measured the water surface profiles at the beginning of each test and at each hour during the test run. At the end of each test, the bed morphology was surveyed using a Laser Scanner "HDS-4500 (Leica Geosystems)" with precision of $\pm 0.001 \mathrm{~m}$. A plan view of Log-Frame Deflector and Log-Deflector is presented in Fig. 2a and Fig. 2b respectively. Stream wise views of scour hole and ridge are shown in Fig. 2c and Fig. 2d., including the main hydraulic and geometric parameters, where $B$ is the channel width, $y_{0}$ is the approach flow depth, $h_{s t}$ is the mean height of the structure, $h_{t w}$ is the tailwater depth, $\Delta y$ is the difference between water surface upstream and downstream of the structure, $z_{m}$ is the maximum scour depth downstream of Log-Frame Deflector, $z_{1 m}$ is the maximum depth of the scour hole at the end of the Log-Deflector, $z_{2 m}$ is the maximum depth of the scour hole close to the channel bank, $l_{m}$ is the maximum length of the scour hole, $z^{\prime}{ }_{m}$ is the maximum height of the ridge, $l_{m}^{\prime}$ is the ridge length in the longitudinal section in which the maximum ridge height occurs, $l_{s t}$ is the length of the structure, $\alpha$ is the structure arms angle with the riverbank. $\alpha=30^{\circ}$ has been selected to be comparable with the previous contribution (Pagliara et al. 2015) in which Log-Deflectors have been studied in straight channel with installation angle of $\alpha=30^{\circ}$. Fig. 2e depicts a transversal section of the channel. As it is shown in Fig. 2e, structure arms were formed by three logs. One tick log that practically is the main part of the structure on the channel bed and defines the height of the structure and two small logs as basement of the structure that were placed inside the channel bed to keep the structure stable. These three logs were attached using wires. Experimental data are shown in Table 1.

Pagliara et al. (2013), defined the densimetric particle Froude number as follows:

$\mathrm{F}_{d}=\frac{Q^{\prime}}{l_{s t} \cdot h_{s t}\left[g\left(G_{s}-1\right) d_{50}\right]^{50}}$

where $Q^{\prime}$ is the effective flow discharge, $G_{s}=\rho_{s} / \rho$, in which $\rho_{s}=$ bed material density and $\rho=$ water density, $d_{50}$ is the mean particle diameter and $g=$ gravitational acceleration. Uniform sand $\left(G_{s}=2.60\right.$, $d_{50}=1.77 \mathrm{~mm}$ with particle uniformity factor $\left.\sigma=\left(d_{84} / d_{16}\right)^{0.5}=1.26\right)$ was used as bed material, $b$ is the total width of the channel occupied with woody structure and $B$ is the channel width. The effective flow discharge was calculate based on ratio $b / B$, so $Q^{\prime}=(b / B) \cdot Q$, where $Q$ is the total channel flow discharge. At the beginning of each experiment, the channel bed was carefully leveled. After each 
test the bed material was mixed in order to maintain the same gradation curve. The current study is based on an inception Froude number based on Shields' criterion, found by Hager and Oliveto (2002) to control the clear water condition. According to Hager and Oliveto (2002) "the Shields' diagram cannot be used directly to establish whether a uniform sediment bed remains stable or not." Therefore, they adopted the inception Froude number, which is a parameter accounting for "the relationship between fluid dynamics, sedimentology, and relative flow depth." In particular, they found that "for equal density of sediment and fluid, the inception Froude number increases with the relative flow depth." This number is useful to verify the clear water conditions. All the tests have been carried out up to when the equilibrium bed condition was reached (one to three hours). The approaching flow Reynolds number was measured at the upstream of the channel setup and varied between $82 \cdot 10^{3}$ and $198 \cdot 10^{3}$, indicating a turbulent flow condition for all the tests. All experiments were carried out in subcritical flow and clear water condition.

\subsection{Dimensional Analysis and Methods}

One of the most important scour morphology features downstream of grade-control structures is the value of the maximum scour depth. Maximum scour depth downstream of woody stream restoration structures is governed by the following functional relationship:

$$
f\left(z_{m}, h_{s t}, h_{t w}, l_{s t}, B, \Delta y, Q^{\prime}, \rho_{s}, \rho, g, d_{50}\right)=0
$$

In which $f$ is a functional symbol. Pagliara and Kurdistani (2013), based on dimensional analysis and incomplete self-similarity (Barenblatt, 1987) as it has been used also by D'Agostino and Ferro (2004) and Scurlock et al. (2012), presented the following non-dimensional functional expression derived from functional relation (1):

$$
\frac{z_{m}}{h_{s t}}=f\left(\frac{l_{s t}}{B}, \frac{h_{t w}}{h_{s t}}, \mathrm{~F}_{d}, \frac{\Delta y}{h_{s t}}\right)
$$

Expression (3) contains all effective parameters on scour phenomena including structure geometry factors, densimetric Froude number and tailwater depth. Pagliara et al. (2015). According to Pagliara

and Kurdistani (2013), the scour parameter $\eta=\mathrm{F}_{d}{ }^{2} \cdot \Delta y / h_{s t}$ was used to derive equations and classify scour morphology. Based on dimensional analysis and experimental data, the general equation (4), for $0.001<\eta<4$ has been derived to predict the maximum scour depth downstream of Log-Deflectors in straight channels that is valid for different values of tailwater depths as follows $\left(\mathrm{R}^{2}=0.91\right)$ : 


$$
\frac{z_{m}}{h_{s t}}=6.6\left(\frac{l_{s t}}{B}\right)\left(\frac{h_{t w}}{h_{s t}}\right)^{-1} \eta^{0.7}
$$

Functional relation (3) can be adopted also to determine the other scour parameters substituting $z_{m}$ with the corresponding variables in the dimensional analysis process. Pagliara et al. (2015) using functional relation (3), derived other equations to predict the maximum scour length, maximum ridge height and length downstream of Log-Deflectors. Because of experimental limitations, they didn't consider the effect of tailwater on the other scour parameters. Therefore, equations (5) to (7) estimate the maximum scour length, maximum ridge height and length respectively for $0.001<\eta<4$ without considering the effect of tailwater.

$$
\begin{aligned}
& \frac{l_{m}}{h_{s t}}=22\left(\frac{l_{s t}}{B}\right) \eta^{0.4} \\
& \frac{z_{m}^{\prime}}{h_{s t}}=1.4\left(\frac{l_{s t}}{B}\right) \eta^{0.4} \\
& \frac{l_{m}^{\prime}}{h_{s t}}=25\left(\frac{l_{s t}}{B}\right) \eta^{0.4}
\end{aligned}
$$

Current 17 experiments include the effect of tailwater depth on the quantity of the main scour and ridge parameters and also show the effect of the geometry of the log-frame deflector on the morphology type of scour and ridge.

\section{Results}

Using the geometry of Log-Frame Deflectors in the experimental process and considering the effect of tailwater depth, new equations have been derived to estimate the main scour parameters downstream of Log-Frame Deflectors. The scour factor $\eta=\mathrm{F}_{d}^{2} \cdot \Delta y / h_{s t}$ is a non-dimensional parameter and covers the effects of flow discharge, water fall over the structure and the height of the structure. Therefore, it appears that using real field observed data in the current experimental limitation ( 0.001 $<\eta<1$ ), it would be possible to predict the scour parameters downstream of Log-Frame Deflectors in the real rivers for $(0.001<\eta<1)$. Fig. 3 compares Eq. (4) with current experimental data, experimental data on spur dikes obtained by Kuhnle et al. $(1999,2002)$ and Log-Deflector data of Pagliara et al. (2015). As there are no data on woody structures in the literature, the closest structure geometry belongs to spur dikes. Therefore, observed data of Kuhnle et al. $(1999,2002)$ that are on $90^{\circ}$ spur dike and angled spur dike respectively have been used to compare with the derived Eq. (4).

Fig 3 shows that Eq. (4) fits well with observed Log-Frame Deflector data within the 30 percent of 
deviation respect to the perfect agreement line and is valid to estimate the maximum scour depth even for both $90^{\circ}$ and angled spur dikes.

Using current study data and considering tailwater ratio as a parameter, the maximum scour hole length could be estimated using Eq. (8) $\left(\mathrm{R}^{2}=0.81\right)$ :

$$
\frac{l_{m}}{h_{s t}}=35\left(\frac{l_{s t}}{B}\right)\left(\frac{h_{t w}}{h_{s t}}\right)^{-1} \eta^{0.4}
$$

Current observed experimental data of Log-Frame Deflectors show considering the tailwater ratio $\left(h_{t w} / h_{s t}\right)$ as a parameter, the maximum ridge height could be predicted using Eq. (9) for the range of tests $(0.001<\eta<1)\left(\mathrm{R}^{2}=0.79\right)$ as follows:

$$
\frac{z_{m}^{\prime}}{h_{s t}}=4.6\left(\frac{l_{s t}}{B}\right)\left(\frac{h_{t w}}{h_{s t}}\right)^{-1.3} \eta^{0.7}
$$

The same elaboration for the maximum length of the ridge leads to find another equation to determine the maximum ridge length for the range of tests $(0.001<\eta<1)\left(\mathrm{R}^{2}=0.93\right)$ as follows:

$$
\frac{l_{m}^{\prime}}{h_{s t}}=65\left(\frac{l_{s t}}{B}\right)\left(\frac{h_{t w}}{h_{s t}}\right)^{-1} \eta^{0.7}
$$

\section{Discussion}

Fig. 4 compares equation (4) with all observed maximum scour depths $z_{m}$ including Log-Deflectors data (Pagliara et al. 2015) showing tailwater ratio $h_{t w} / h_{s t}$ as parameter. It depicts that tailwater depth plays a direct role to change the maximum scour depth in the experimental data range $(0.001<\eta<$ 1). Eq. (8) is compared with observed scour length data including Log-Deflector data (Pagliara et al. 2015) in Fig. 5. It confirms that Eq. (8) is valid to determine the maximum scour length downstream of both Log-Deflectors and Log-Frame Deflectors in the range of $0.001<\eta<1\left(\mathrm{R}^{2}=0.81\right)$ considering tailwater ratio $h_{t w} / h_{s t}$ as parameter.

All observed ridge height data including current study data and Log-Deflector data (Pagliara et al. 2015) have been compared with Eq. (9) in Fig. 6 and it demonstrates that Eq. (9) well fits with the scattered ridge height data even with Log-Deflectors data considering the effect of the tailwater depth. Experimental observations of the length of the ridge including Pagliara et al. (2015) data are compared in Fig. 7. The same as other parameters, the effect of the tailwater depth has been shown 
as data labels. Fig. 7 shows that increasing tailwater depth decreases the ridge length and data trend can be represented by the Eq. (10) for $0.001<\eta<1\left(\mathrm{R}^{2}=0.93\right)$.

Fig. 8 compares morphology formation in the presence of single wing Log-Deflector and single LogFrame Deflector for different hydraulic conditions. Fig. 8a demonstrates morphology Type C for single wing Log-Deflector that is formed for $\mathrm{F}_{d}=1.4, \eta=0.1$, and $\Delta y / h_{s t}=0.05$ while Fig. $8 \mathrm{~b}$ shows the same morphology type for the same hydraulic conditions for Log-Frame Deflector. This comparison has been done for the other hydraulic conditions. Fig. 8c shows morphology Type D for single wing Log-Deflector including a very deep scour hole close to the channel bank and a small scour hole at the end of the structure. This test has been done under the hydraulic conditions including $\mathrm{F}_{d}=3.2, \eta=0.4$, and $\Delta y / h_{s t}=0.04$. Maintaining the same hydraulic conditions and installing a LogFrame deflector, results to change the morphology type from Type D to Type $\mathrm{C}$ that is shown in Fig. $8 \mathrm{~d}$. Therefore, there is no more scour hole close to the channel bank and a unique deep scour hole occurs at the end of the structure. Fig. 8e depicts the morphology Type $\mathrm{C}$ for very small value of $\eta=$ 0.06 and Fig. $8 \mathrm{f}$ confirms that installing Log-Frame Deflector instead of Log-Deflector also leads to morphology Type C. Comparing these six figures indicates that for very small values of $F_{d}$ and bigger values of $\Delta y / h_{s t}$, morphology Type $\mathrm{C}$ occurs while for big values of $\mathrm{F}_{d}$ and smaller values of $\Delta y / h_{s t}$, morphology Type D occurs. In other words, the main effective parameter is the densimetric Froude number and it means that also in the case of the presence of a big water fall over the structure, if $F_{d}$ is small, there would not occur a scour hole close to the riverbank and it leads to morphology Type C. Fig. 8 (g-j) confirm this hypothesis. Fig. $8 \mathrm{~g}$ presents a morphology Type D for hydraulic conditions containing $\mathrm{F}_{d}=2.5, \eta=0.15$, and $\Delta y / h_{s t}=0.02$ which installing Log-Frame Deflector instead of single wing Log-Deflector, morphology changes from Type D to Type C (see Fig. 8h). Also for the other hydraulic conditions $\mathrm{F}_{d}=2.1, \eta=0.19$, and $\Delta y / h_{s t}=0.04$ the same situation has been observed which is shown in Fig. 8(i,j). This means that for high values of $\mathrm{F}_{d}$ and small values of $\Delta y / h_{s t}$ in the presence of the Log-Deflector, morphology Type D occurs with a deep scour hole close to the channel bank and by installing the Log-Frame Deflector there is no more scour hole close to the channel bank and morphology changes from Type D (Fig. 8i) to Type C (Fig. 8j).

Fig. 9(a-j) shows morphology types downstream of double Log-Frame Deflectors. It appears that in all previous explained hydraulic conditions, in the presence of Log-Frame Deflectors, morphology Type C occurs and installing the double Log-Frame Deflector results to have a more concentrated scour hole in the center of the channel even for high values of $F_{d}$ and $\eta$. For example, Fig. 9c shows a morphology Type $\mathrm{C}$ for $\mathrm{F}_{d}=3.2, \eta=0.4$, and $\Delta y / h_{s t}=0.04$ in the presence of Log-Frame Deflector and Fig. 9d demonstrates the same morphology Type $\mathrm{C}$ for installation of double Log-Frame 
Deflector but it is clearly visible that the scour hole is more concentrated in the center of the channel respect to the installation of single Log-Frame Deflector.

Figure 10 presents photos of two morphological Types C and D. Fig. 10a shows morphology Type D downstream of single wing Log-Deflector. It shows a deep scour hole close to the channel bank and a small scour hole at the end of the structure. Fig. 10b demonstrates that installing Log-Frame Deflector in the same structure dimensions and arm angle, for the same hydraulic conditions changes morphology Type D to Type $\mathrm{C}$ and there is only one scour hole at the end of the structure and there is no more scour hole at the channel bank. Fig. 10c depicts morphology Type C for double Log-Frame Deflector installed in the channel for the same hydraulic conditions and structure geometry of Fig. $10 \mathrm{a}, \mathrm{b}$.

Pagliara et al. (2015) showed that both densimetric Froude number and $\Delta y / h_{s t}$ are important parameters to classify the scour morphology downstream of Log-Deflectors. Fig. 11a depicts that increasing $\mathrm{F}_{d}$ and decreasing $\Delta y / h_{s t}$ leads to morphology Type D for Log-Deflectors while in the case of decreasing $\mathrm{F}_{d}$ and increasing $\Delta y / h_{s t}$, morphology Type $\mathrm{C}$ occurs downstream of Log-Deflectors. As it is explained before, all tests were done in clear water condition then to avoid sediment transport, high discharge tests have been done in high tailwater depth conditions. As a matter of fact, all data in Fig. 11a showing high values of $\eta$ are related to high discharge tests with high tailwater depths that lead to morphology Type D. Fig. 11b shows that in the case of installing Log-Frame Deflector, just morphology Type $\mathrm{C}$ occurs even for high values of $\mathrm{F}_{d}$.

\section{Conclusions}

A supplemental series of experiments was conducted to investigate the scour morphology downstream of Log-Frame Deflectors in compare with Log-Deflector experiments which were done by Pagliara et al. (2015). Based on dimensional analysis, empirical relationships were found to predict the maximum scour depth for different combinations of hydraulic conditions and structures geometry. Densimetric Froude number, drop height, tailwater and height of the structure are the main parameters influencing the maximum scour depth, the maximum scour length, maximum ridge height and the maximum ridge length. Results showed that for any hydraulic condition and Log-Frame Deflectors structure geometry, increasing the tailwater depth decreases the values of all scour parameters. New expressions have been presented to predict scour characteristics considering tailwater ratio $h_{t w} / h_{s t}$. Results showed, that in the classification of scour types in the presence of Log-Frame Deflectors even for the high values of densimetric Froude number, morphology Type $\mathrm{C}$ occurs with forming the scour 
hole in the center of the channel at the end of the structure arm while in the presence of Log-Deflectors for the high values of densimetric Froude number, morphology Type D occurs.

\section{NOTATION}

$B \quad=$ channel width

$d_{50} \quad=$ mean particle diameter

$f \quad=$ functional symbol

$\mathrm{F}_{d} \quad=$ densimetric Froude number $=Q^{\prime} /\left\{l \cdot h_{s t}\left[g\left(G_{s^{-}}-1\right) d_{50}\right]^{0.5}\right\}$

$g \quad=$ gravitational acceleration

$G_{s} \quad=\rho_{s} / \rho$

$h_{s t} \quad=$ height of the structure (average height of the logs)

$l_{s t} \quad=$ length of the structure

$l_{m} \quad=$ scour length downstream of the structure

$l_{m}^{\prime} \quad=$ ridge length

$Q \quad=$ flow discharge

$Q^{\prime} \quad=$ effective flow discharge $=(b / B) \cdot Q$

$y_{0} \quad=$ approach flow depth

$z_{m} \quad=$ maximum scour depth downstream of Log-Frame Deflector

$z_{1 m}=$ maximum depth of the scour hole at the end of the Log-Deflector

$z_{2 m} \quad=$ maximum depth of the scour hole close to the channel bank

$z_{m}^{\prime} \quad=$ maximum ridge height

$\Delta y \quad=$ difference between water surface upstream and downstream of the structure

$\alpha \quad=$ structure arms angle with the river bank

$\eta \quad=\mathrm{F}_{d}^{2} \cdot \Delta y / h_{s t}$

$\rho \quad=$ water density

$\rho_{s} \quad=$ bed material density

$\sigma \quad=$ particle uniformity factor $=\left(d_{84} / d_{16}\right)^{0.5}$ 


\section{References}

Barenblatt, G. I. 1987. Dimensional Analysis. Gordon and Breach Science Publishers. ISBN 3-7186-0438-8.

Bhuiyan, F., Hey, R. D. and Wormleaton, P. R. 2007. hydraulic Evaluation of W-Weir for River Restoration. J. Hydraul. Eng.-ASCE 133(6), 596-609.

Bhuiyan, F., Hey, R. D. and Wormleaton, P. R. 2010. Bank-Attached Vanes for Bank Erosion Control and Restoration of River Meanders. J. Hydraul. Eng.-ASCE 136(9), 583-596.

D’Agostino, V. and Ferro, V. 2004. Scour on Alluvial Bed Downstream of Grade-Control Structures. J. Hydraul. Eng., ASCE, 130(1), 24-37.

Galia Tomáš, Škarpich Václav, Hradecký Jan, Přibyla Zdeněk. Effect of grade-control structures at various stages of their destruction on bed sediments and local channel parameters, Geomorphology 2015, doi: 10.1016/j.geomorph.2015.10.033.

Gillilan, S., Boyd, K., Hoitsma, T. \& Kauffman, M. 2005. Challenges in developing and implementing ecological standards for geomorphic river restoration projects: a practitioner's response to Palmer et al. (2005). Journal of Applied Ecology, 42, 223-227.

Guan, D., Melville, B., and Friedrich, H. 2014a. Flow Patterns and Turbulence Structures in a Scour Hole Downstream of a Submerged Weir. J. Hydraul. Eng.-ASCE 140(1), 68-76.

Guan, D., Melville, B.W., and Friedrich, H. 2014b. Live-Bed Scour at Submerged Weirs. J. Hydraul. Eng.-ASCE 141 (2), $04014071(1-9)$.

Hager, W. H. and Oliveto, G. 2002. Shields' Entrainment Criterion in Bridge Hydraulics. J. Hydraul. Eng.-ASCE 128(5), $538-542$.

Jansen, P. Ph., Bendegom, L. van, Berg, J. van den, Vries, M. de, and Zanen, A., Eds. 1979. Principles of river engineering. Pitman Publishing Ltd. London, England.

Jamieson, E. C., Rennie, C. D., and Townsend, R. D. 2013a. 3D flow and sediment dynamics in a laboratory channel bend with and without stream barbs. J. Hydraul. Eng.-ASCE 139(2), 154-166.

Jamieson, E. C., Rennie, C. D., and Townsend, R. D. 2013b. Turbulence and Vorticity in a Laboratory Channel Bend at Equilibrium Clear-Water Scour with and without Stream Barbs. J. Hydraul. Eng.-ASCE 139(3), 259-268.

Khosronejad, A., Hill, C., Kang, S., and Sotiropoulos, F. 2013. Computational and experimental investigation of scour past laboratory models of stream restoration rock structures. Advances in Water Resources, 54, 191-207.

Khosronejad, A., Kozarek, J. L., and Sotiropoulos, F. 2014a. Simulation-based approach for stream restoration structure design: model development and validation. Journal of Hydraulic Engineering, 140(7), 04014042-1-16.

Khosronejad, A., Kozarek, J. L., Palmsten, M. L., and Sotiropoulos, F. 2014b. Numerical simulation of large dunes in meandering streams and rivers with in-stream rock structures. Advances in Water Resources. doi: 10.1016/j.advwatres.2014.09.007.

Kuhnle et al., 1999. Geometry of Scour Holes Associated with 90 Spur Dikes. J. Hydraul. Eng.-ASCE 125(9), 972-978. Kuhnle et al., 2002. Local Scour Associated with Angled Spur Dikes. J. Hydraul. Eng.-ASCE 128(12), 1087-1093. 
Kurdistani, S.M. and Pagliara S. 2015. Scour Characteristics Downstream of Grade-Control Structures: Log-Vane and Log-Deflectors Comparison. World Environmental and Water Resources Congress 2015: Floods, Droughts, and Ecosystems - ASCE. 1831-1840.

Leopold, Luna B. 1994. River Morphology as an Analog to Darwin's Theory of Natural Selection. Proceedings of the American Philosophical Society, 138(1), 31-47.

Lenzi, Mario A. and Comiti, F. 2003. Local scouring and morphological adjustments in steep channels with check-dam sequences. Geomorphology 55, 97-109.

Melville, B.W., 1992. Local Scour at Bridge Abutments. J. Hydraul. Eng.-ASCE 118(4), 615-631.

Melville, B.W., 2014. Scour at Various Hydraulic Structures: Sluice gates, Submerged bridges, Low weirs. $5^{\text {th }}$ International Symposium on Hydraulic Structures. Brisbane, Australia, Hydraulic Structures and Society: Engineering Challenges and Extremes, ISBN 9781742721156 - DOI: 10.14264/uq1.2014.10.

Odgard, A.J. and Mosconi, C.E. 1987. Stream bank Protection by Submerged Vanes. J. Hydraul. Eng., ASCE, 113(4), 520-536.

Odgard, A.J. and Spoljaric, A. 1986. Sediment Control by Submerged Vanes. J. Hydraul. Eng., ASCE, 112(12), 11641181 .

Odgard, A.J. and Wang, Y. 1991. Sediment Management with Submerged Vanes. II: Applications. J. Hydraul. Eng., ASCE, 117(3), 284-302.

Pagliara, S., Kurdistani, S.M. 2013. Scour downstream of cross-vane structures. J. Hydro-Env. Res. 7(4), $236-242$.

Pagliara, S., Kurdistani, S. M. and Santucci, I. 2013. Scour Downstream of J-Hook Vane Structures in Straight Horizontal Channels. Acta Geophysica 61(5), 1211-1228.

Pagliara, S. and Kurdistani, S.M. 2014. Scour characteristics downstream of grade-control structures. River Flow 2014, Schleiss et al. (Eds) (C) 2014 Taylor \& Francis Group, London, ISBN 978-1-138-02674-2, 2093-2098.

Pagliara, S., Kurdistani, S. M., and Cammarata, L. 2014a. Scour of Clear Water Rock W-Weirs in Straight Rivers. J. Hydraul. Eng.-ASCE 140(4), 06014002(1-7).

Pagliara, S., Hassanabadi, L.S., and Kurdistani S.M. 2014b. Log-Vane Scour in Clear Water Condition. River Research and Applications, DOI: 10.1002/rra.2799.

Pagliara, S., Hassanabadi, L., and Kurdistani, S.M. 2015. Clear Water Scour Downstream of Log Deflectors in Horizontal Channels. J. Irrig. Drain Eng.-ASCE Doi:10.1061/(ASCE)IR.1943-4774.0000869, 04015007(1-8).

Pagliara, S. and Kurdistani, S.M. 2015. Clear water scour at J-Hook Vanes in channel bends for stream restorations. Ecological Engineering, (83), 386-393, doi: 10.1016/j.ecoleng.2015.07.003.

Pagliara, S., Kurdistani, S.M., Palermo, M. and Simoni, D. 2016. Scour due to rock sills in straight and curved horizontal channels, Journal of Hydro-environment Research, doi: 10.1016/j.jher.2015.07.002.

Przedwojski, B. 1995. Bed topography and local scour in rivers with banks protected by groynes. J. Hydraul. Res. 33(2), 257-273. 
Roca, M., Martín-Vide, J. P., and Blanckaert, K. 2007. Reduction of bend scour by an outer bank footing: Footing design and bed topography. J. Hydraul. Eng.-ASCE 133(2), 139-147.

Roca, M., Blanckaert, K. and Martín-Vide, J. P. 2009. Reduction of bend scour by an outer bank footing: Flow Field and Turbulence, J. Hydraul. Eng.-ASCE 135(5), 361-368.

Rosgen, D.L. 2001. The Cross-Vane, W-weir and J-Hook Vane Structures: Their Description, Design and Application for Stream Stabilization and River Restoration. paper presented at Conference on Wetland Engineering and River Restoration, Reston, Va.

Scurlock, S.M., Cox, A. L., Thornton, C. I. and Baird, D. C. 2012a. Maximum Velocity Effects from Vane-Dike Installations in Channel Bends. paper presented at World Environmental and Water Resources Congress 2614-2626.

Scurlock, S.M., Thornton,C. I. and Abt S. R. 2012b. Equilibrium Scour Downstream of Three-dimensional Grade-control Structures. J. Hydraul. Eng.-ASCE 138(2), 167-176.

Simon Andrew, Darby Stephen E. Effectiveness of grade-control structures in reducing erosion along incised river channels: the case of Hotophia Creek, Mississippi. Geomorphology 42 (2002) 229-254.

Zhou, T. and Endreny, T. 2011. Meander hydrodynamics initiated by river restoration deflectors. Hydrological Processes, 26(22), 3378-3392.

Table 1 Experimental test ranges

\begin{tabular}{|c|c|c|c|c|c|c|c|c|c|c|c|c|}
\hline Test & $Q\left(\mathrm{~m}^{3} / \mathrm{s}\right)$ & $\alpha^{\circ}$ & $l_{s t} / B$ & $\Delta y(\mathrm{~m})$ & $h_{s t}(\mathrm{~m})$ & $h_{t w}(\mathrm{~m})$ & $b / B$ & No. deflectors & $z_{m}(\mathrm{~m})$ & $z^{\prime}{ }_{m}(\mathrm{~m})$ & $l_{m}(\mathrm{~m})$ & $l_{m}^{\prime}(\mathrm{m})$ \\
\hline 1 & 0.0300 & 30 & 0.663 & 0.0046 & 0.0850 & 0.0920 & 0.338 & 1 & 0.0490 & 0.0340 & 0.4950 & 0.6160 \\
\hline 2 & 0.0350 & 30 & 0.663 & 0.0037 & 0.0850 & 0.1171 & 0.338 & 1 & 0.0490 & 0.0300 & 0.5060 & 0.5160 \\
\hline 3 & 0.0550 & 30 & 0.663 & 0.0020 & 0.0850 & 0.1584 & 0.338 & 1 & 0.0470 & 0.0340 & 0.6010 & 0.5670 \\
\hline 4 & 0.0200 & 30 & 0.663 & 0.0057 & 0.0850 & 0.0691 & 0.338 & 1 & 0.0500 & 0.0330 & 0.6620 & 0.5970 \\
\hline 5 & 0.0450 & 30 & 0.663 & 0.0023 & 0.0850 & 0.1527 & 0.338 & 1 & 0.0550 & 0.0430 & 0.4410 & 0.3580 \\
\hline 6 & 0.0200 & 30 & 0.663 & 0.0070 & 0.0550 & 0.0590 & 0.338 & 1 & 0.0650 & 0.0570 & 0.9050 & 1.0900 \\
\hline 7 & 0.0300 & 30 & 0.663 & 0.0023 & 0.0550 & 0.0895 & 0.338 & 1 & 0.0460 & 0.0390 & 0.5500 & 0.6120 \\
\hline 8 & 0.0450 & 30 & 0.663 & 0.0020 & 0.0550 & 0.1233 & 0.338 & 1 & 0.0540 & 0.0330 & 0.5830 & 1.1200 \\
\hline 9 & 0.0550 & 30 & 0.663 & 0.0012 & 0.0550 & 0.1552 & 0.338 & 1 & 0.0570 & 0.0310 & 0.4400 & 0.6800 \\
\hline 10 & 0.0200 & 30 & 0.663 & 0.0080 & 0.085 & 0.0790 & 0.338 & 2 & 0.0770 & 0.0380 & 0.5480 & 0.6030 \\
\hline 11 & 0.0300 & 30 & 0.663 & 0.0025 & 0.085 & 0.1125 & 0.338 & 2 & 0.0620 & 0.0320 & 0.5550 & 0.6890 \\
\hline 12 & 0.0450 & 30 & 0.663 & 0.0037 & 0.085 & 0.1509 & 0.338 & 2 & 0.0770 & 0.0370 & 0.5820 & 0.5740 \\
\hline 13 & 0.0550 & 30 & 0.663 & 0.0015 & 0.085 & 0.1698 & 0.338 & 2 & 0.0640 & 0.0400 & 0.6170 & 0.5910 \\
\hline 14 & 0.0200 & 30 & 0.663 & 0.0011 & 0.055 & 0.0674 & 0.338 & 2 & 0.0300 & 0.0200 & 1.2410 & 1.1680 \\
\hline 15 & 0.0300 & 30 & 0.663 & 0.0017 & 0.055 & 0.0973 & 0.338 & 2 & 0.0530 & 0.0330 & 0.3790 & 0.9350 \\
\hline 16 & 0.0450 & 30 & 0.663 & 0.0029 & 0.055 & 0.1240 & 0.338 & 2 & 0.0640 & 0.0250 & 0.5610 & 0.7150 \\
\hline 17 & 0.0550 & 30 & 0.663 & 0.0098 & 0.055 & 0.1586 & 0.338 & 2 & 0.0480 & 0.0610 & 0.5940 & 0.5360 \\
\hline
\end{tabular}



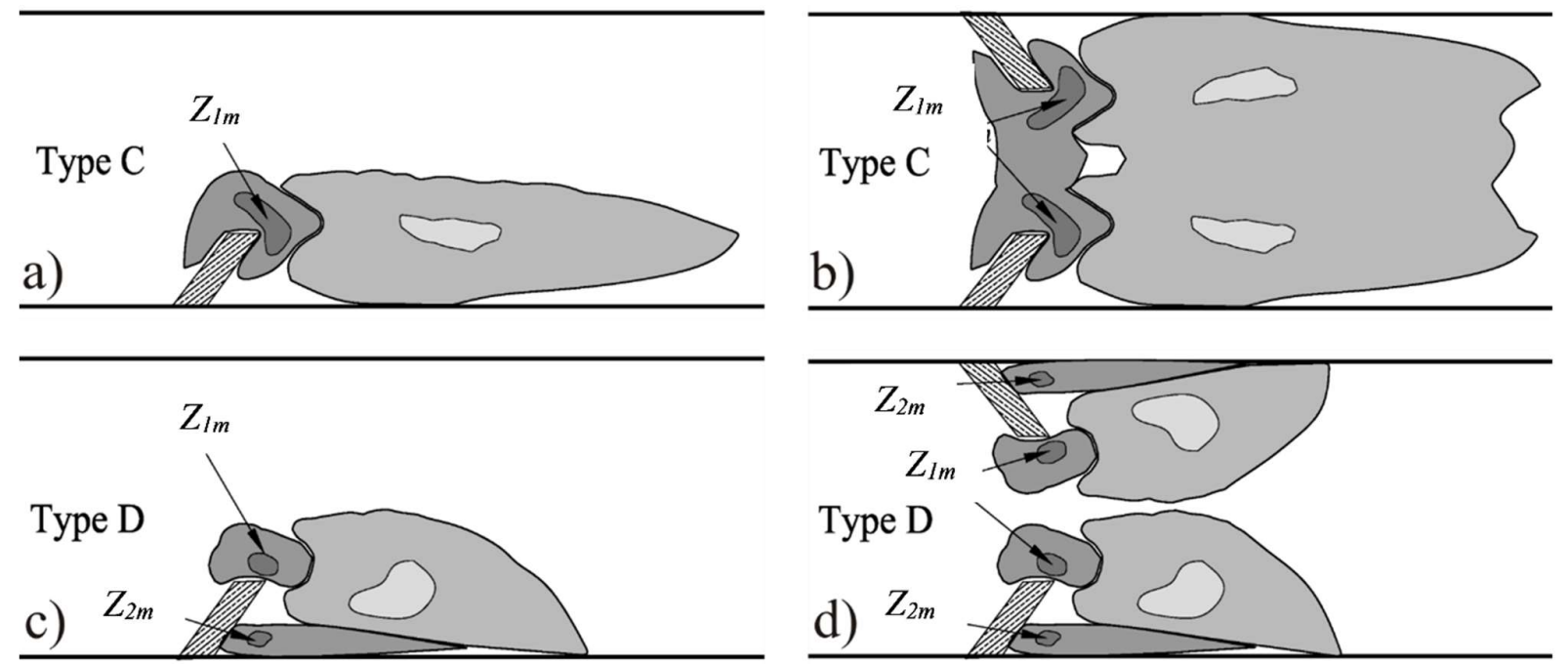

Fig. 1 a) Morphology Type C (no scour hole close to the channel bank) for single wing Log-Deflectors, b) Morphology Type C for double wing Log-Deflectors, c) Morphology Type D (deep scour hole close to the channel bank) for single wing Log-Deflectors and d) Morphology Type D for double wing Log-Deflectors. 


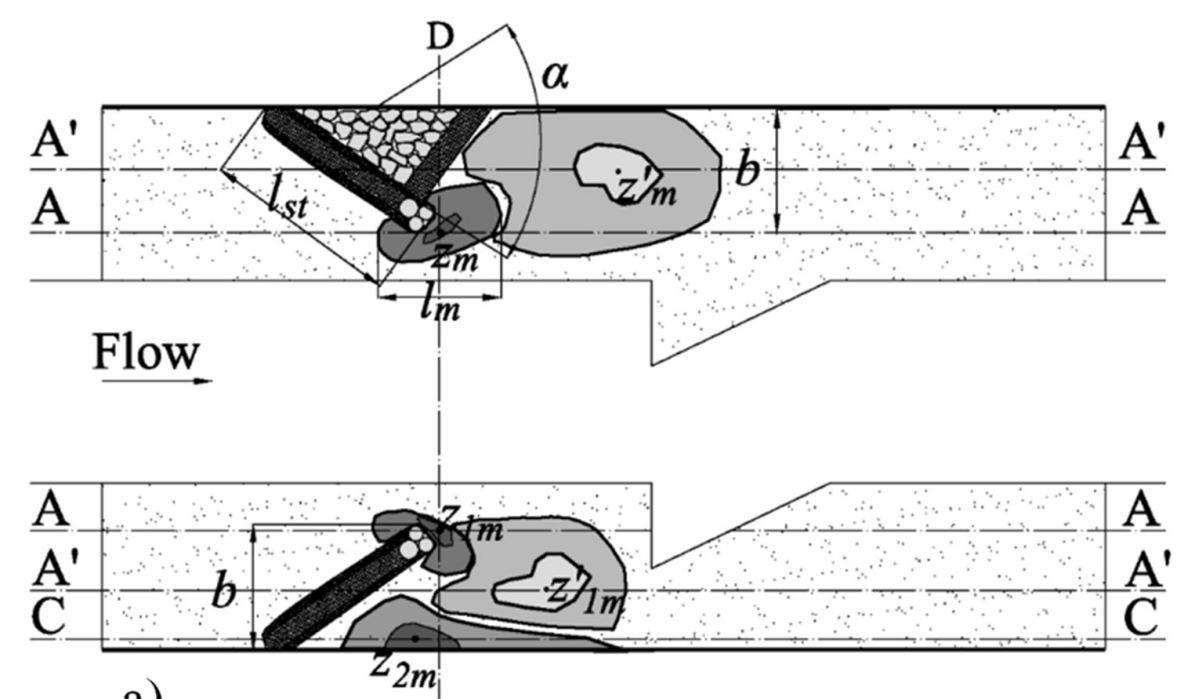

a) $\quad \mathrm{D}$
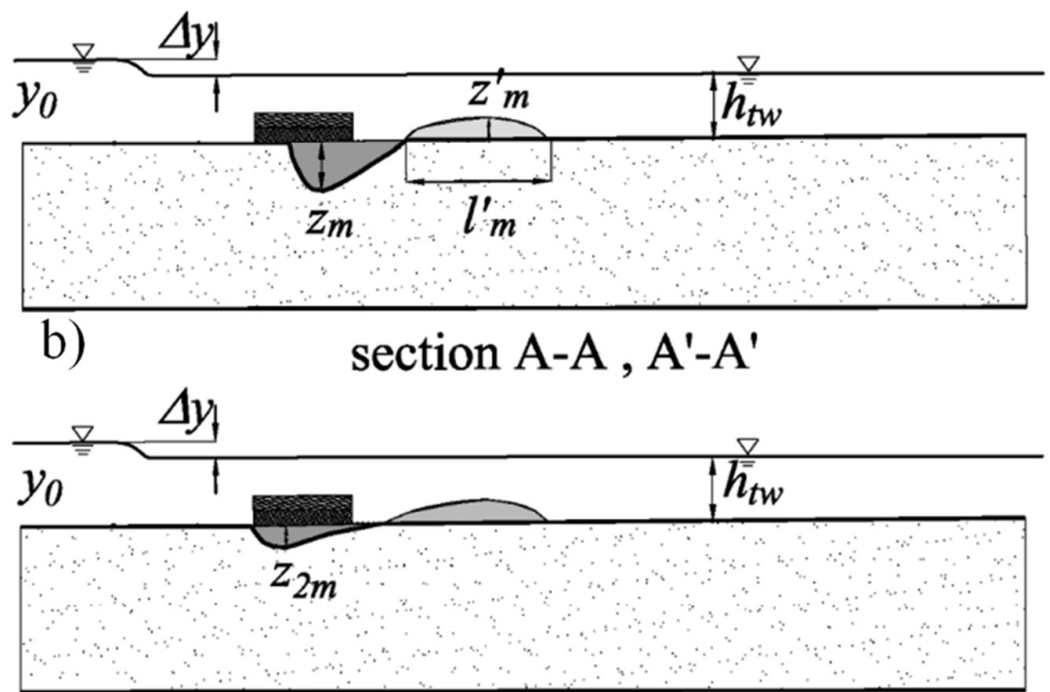

c)

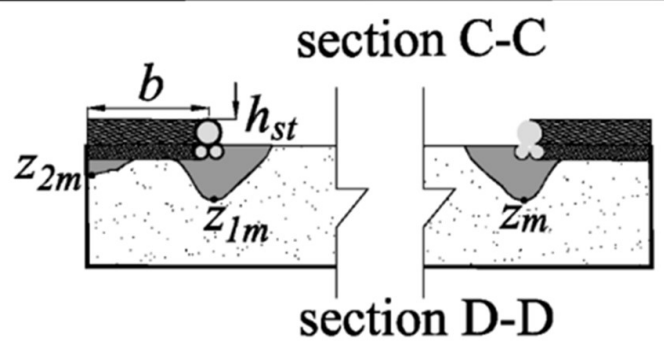

Fig. 2 a) plan view of the Log-Frame Deflector b) plan view of the Log-Deflector c) longitudinal profile A-A and A'-A' d) longitudinal profile C-C e) cross-section D-D. 


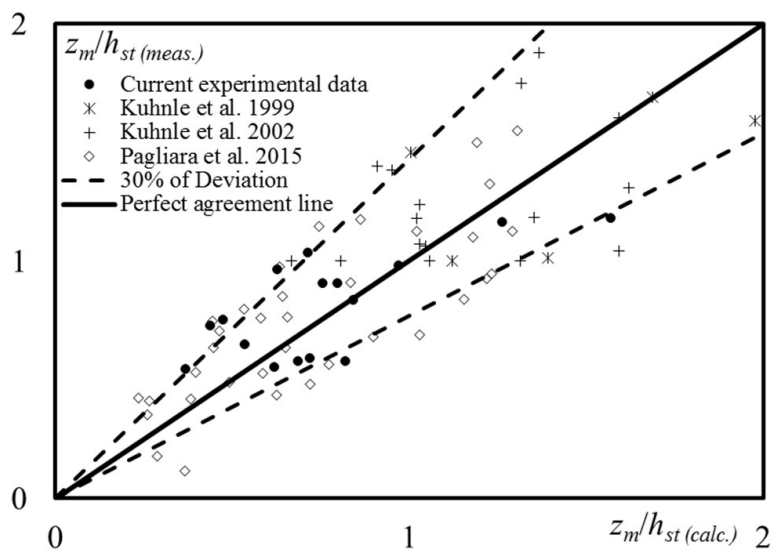

Fig. 3 Comparison of calculated (using equation 4) and measured values of $z_{m} / h_{s t}$.

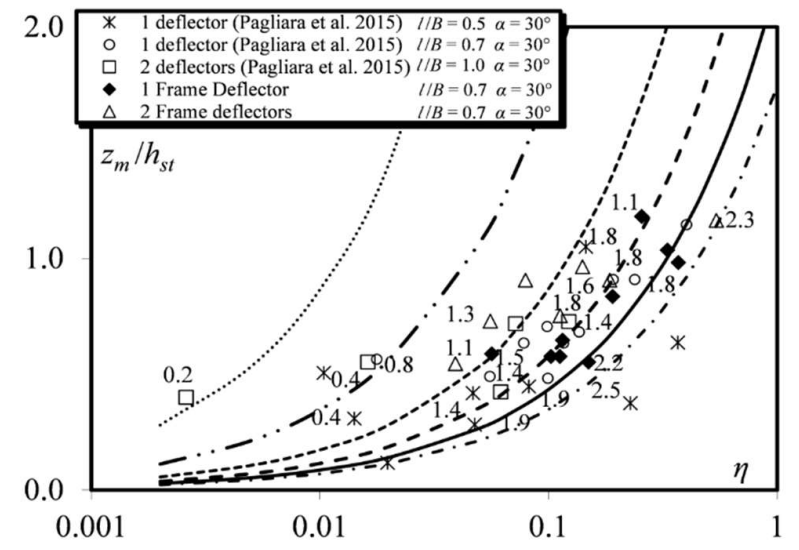

Fig. 4 Comparison of experimental data with equation (4) $h_{t w} / h_{s t}=0.2[\cdots \cdots \cdot], h_{t w} / h_{s t}=0.5[-\cdot \cdot-\cdot \cdot], h_{t w} / h_{s t}=1.0[------]$, $h_{t w} / h_{s t}=1.5[---], h_{t w} / h_{s t}=2.0[\square] h_{t w} / h_{s t}=2.5[-\cdot-\cdot-]$

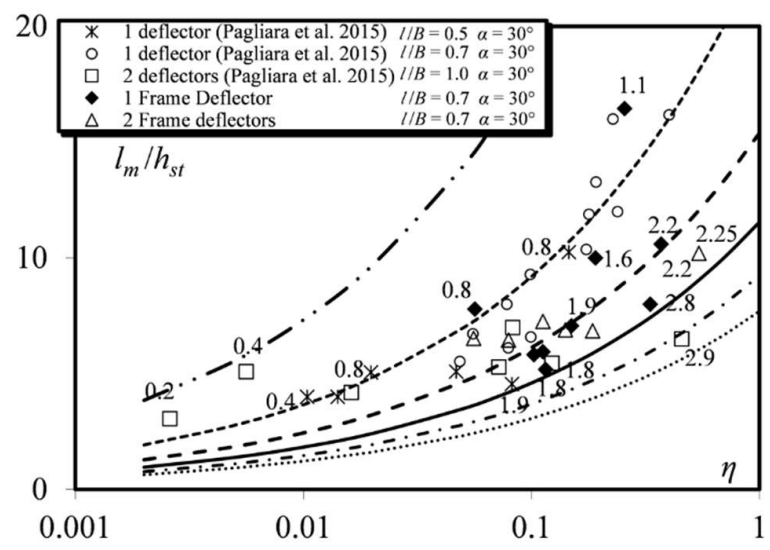

Fig. 5 comparison Eq. (8) with all experimental data for $h_{t w} / h_{s t}=0.5[-\cdot \cdot-\cdot \cdot], h_{t w} / h_{s t}=1.0[------], h_{t w} / h_{s t}=1.5[----]$, $h_{t w} / h_{s t}=2.0[-], h_{t w} / h_{s t}=2.5[-\cdot-\cdot], h_{t w} / h_{s t}=3.0[\cdots \cdots \cdots]$. 


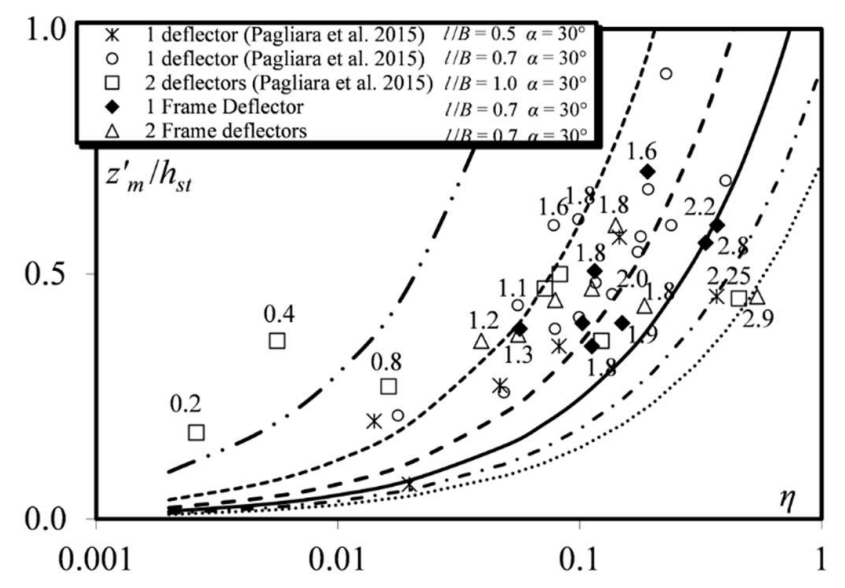

Fig. 6 comparison Eq. (9) with all experimental data for $h_{t w} / h_{s t}=0.5[-\cdot \cdot-\cdot \cdot], h_{t w} / h_{s t}=1.0[------], h_{t w} / h_{s t}=1.5[----]$, $h_{t w} / h_{s t}=2.0[-], h_{t w} / h_{s t}=2.5[-\cdot--], h_{t w} / h_{s t}=3.0[\cdots \cdots \cdots]$.

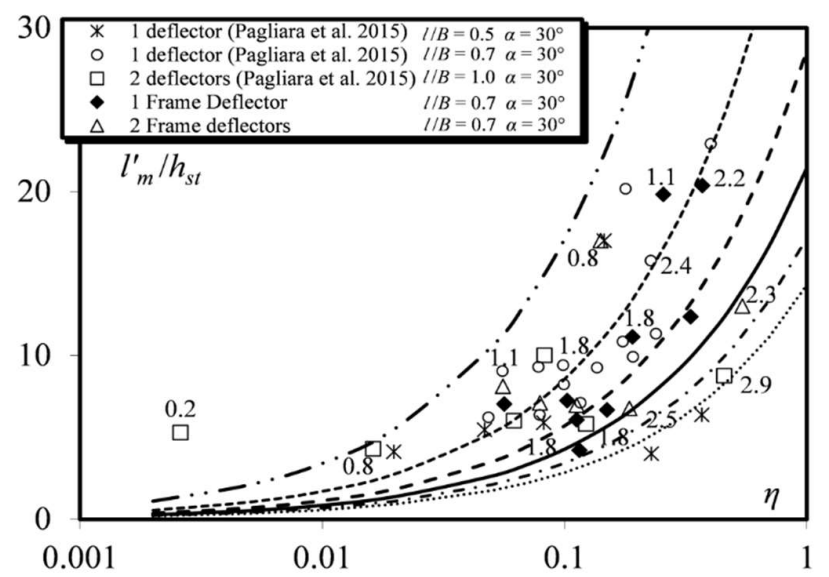

Fig. 7 comparison Eq. (10) with all experimental data for $h_{t w} / h_{s t}=0.5[-\cdot \cdot-\cdot \cdot], h_{t w} / h_{s t}=1.0[------], h_{t w} / h_{s t}=1.5[----]$, $h_{t w} / h_{s t}=2.0[-], h_{t w} / h_{s t}=2.5[-\cdot--], h_{t w} / h_{s t}=3.0[\cdots \cdots \cdots]$. 

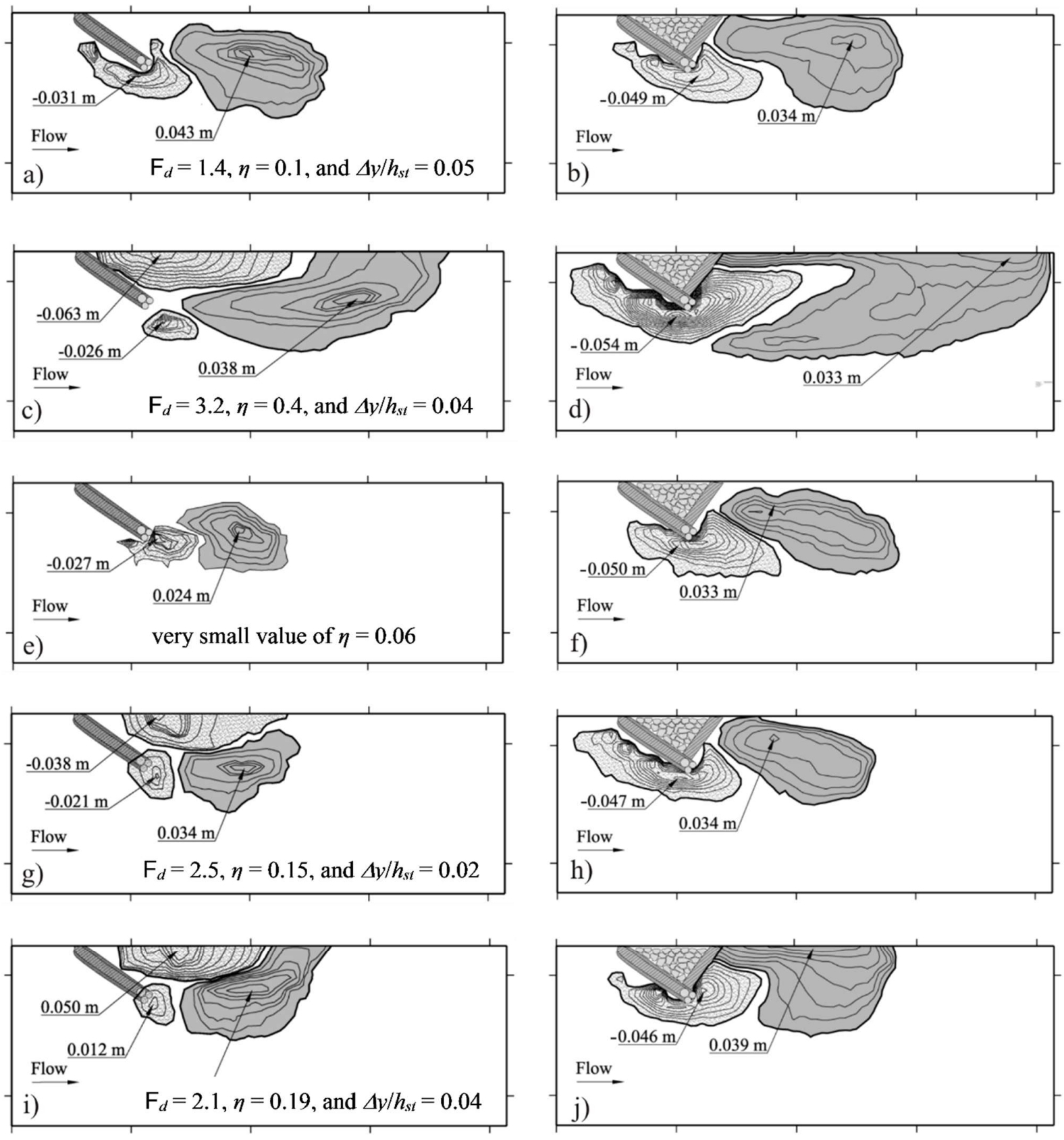

Fig. 8 a) morphology Type $C$ for single wing Log-Deflector $\left(F_{d}=1.4, \eta=0.1\right.$, and $\left.\Delta y / h_{s t}=0.05\right)$, b) morphology Type $\mathrm{C}$ for the same hydraulic conditions for Log-Frame Deflector c) morphology Type D for single wing Log-Deflector $\left(\mathrm{F}_{d}\right.$ $=3.2, \eta=0.4$, and $\left.\Delta y / h_{s t}=0.04\right)$, d) changing morphology Type $\mathrm{D}$ to Type $\mathrm{C}$ by installing a Log-Frame Deflector for the same hydraulic conditions of Fig. 3c, e) the morphology Type $\mathrm{C}$ for very small value of $\eta=0.06, \mathrm{f}$ ) morphology Type $\mathrm{C}$ occurred also for Log-Frame deflector, g) morphology Type D for $\left(\mathrm{F}_{d}=2.5, \eta=0.15\right.$, and $\left.\Delta y / h_{s t}=0.02\right)$, h) changing morphology from Type D to Type C by installing Log-Frame Deflector, i) morphology Type D for $\left(\mathrm{F}_{d}=2.1, \eta=0.19\right.$, and $\left.\Delta y / h_{s t}=0.04\right)$, j) morphology Type $\mathrm{C}$ for the same hydraulic conditions for Log-Frame Deflector. 

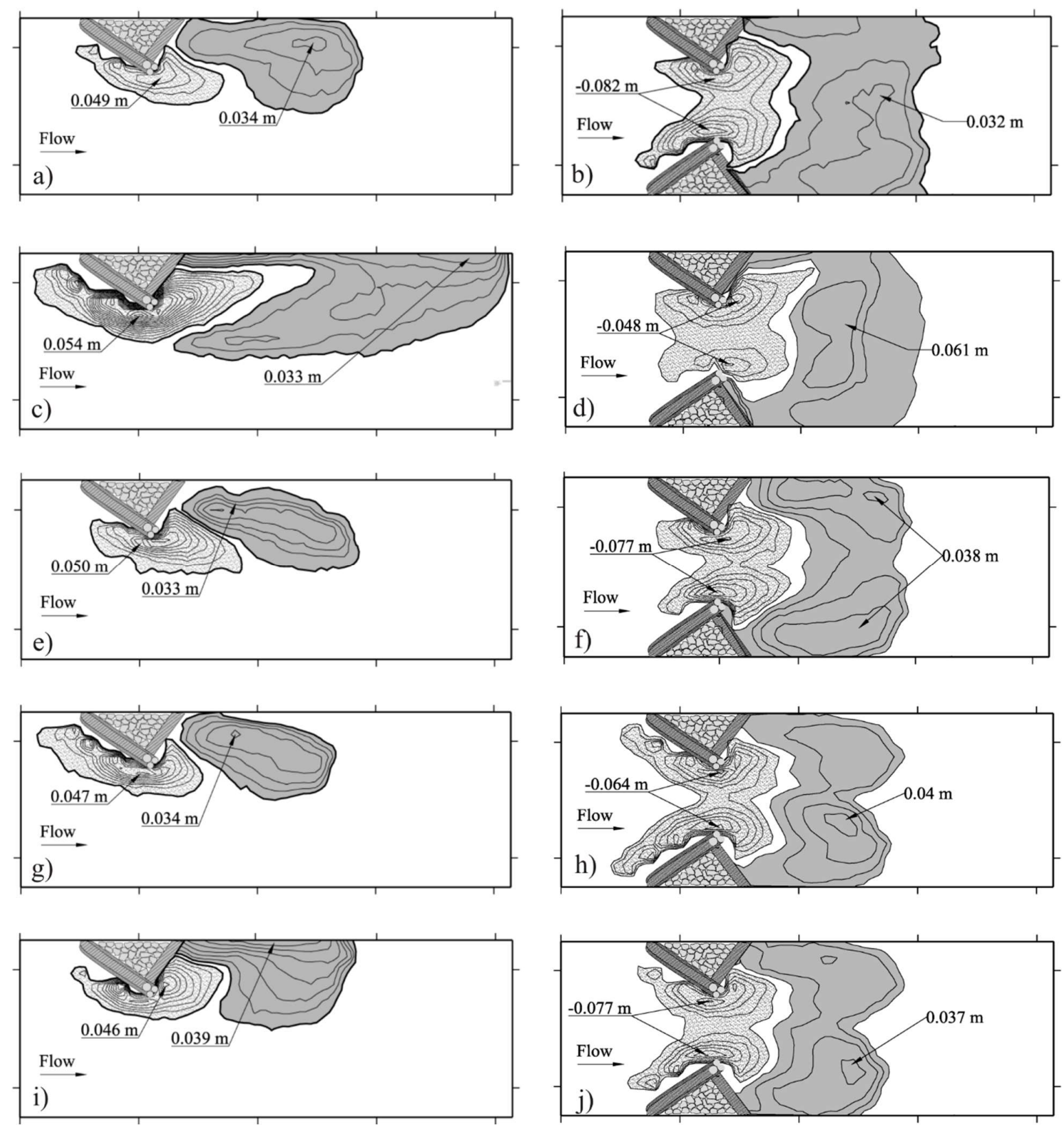

Fig. 9 a) morphology Type $\mathrm{C}$ for single Log-Frame Deflector $\left(\mathrm{F}_{d}=1.4, \eta=0.1\right.$, and $\left.\Delta y / h_{s t}=0.05\right)$, b) morphology Type $\mathrm{C}$ for the same hydraulic conditions for double Log-Frame Deflector c) morphology Type C for single Log-Frame Deflector $\left(\mathrm{F}_{d}=3.2, \eta=0.4\right.$, and $\left.\Delta y / h_{s t}=0.04\right)$, d) morphology Type C installing double Log-Frame Deflector for the same hydraulic conditions, e) the morphology Type $C$ for very small value of $\eta=0.06$, f) morphology Type $C$ occurred also for double Log-Frame deflector, $\mathrm{g})$ morphology Type $\mathrm{C}$ for $\left(\mathrm{F}_{d}=2.5, \eta=0.15\right.$, and $\left.\left.\Delta y / h_{s t}=0.02\right), \mathrm{h}\right)$ morphology Type $\mathrm{C}$ by installing Log-Frame Deflector for the same hydraulic conditions, i) morphology Type $\mathrm{C}$ for $\left(\mathrm{F}_{d}=2.1, \eta=\right.$ 0.19 , and $\left.\Delta y / h_{s t}=0.04\right) \mathrm{j}$ ) morphology Type C for the same hydraulic conditions for double Log-Frame Deflector. 

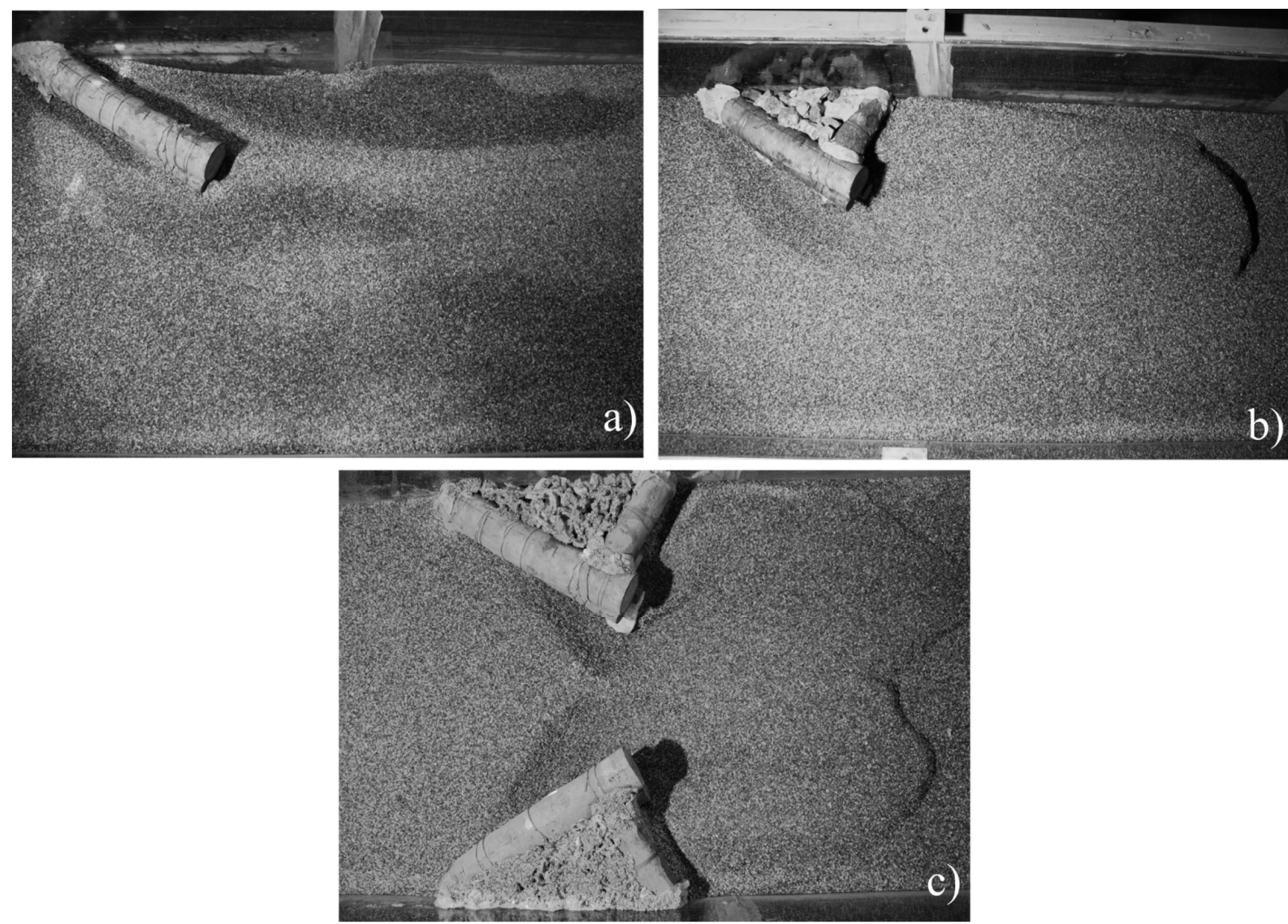

Fig. 10 a) morphology Type D downstream of single wing Log-Deflector, b) changing morphology Type D to Type C by installing Log-Frame Deflector, c) morphology Type C for double Log-Frame Deflector installed in the channel for the same hydraulic conditions and structure geometry.
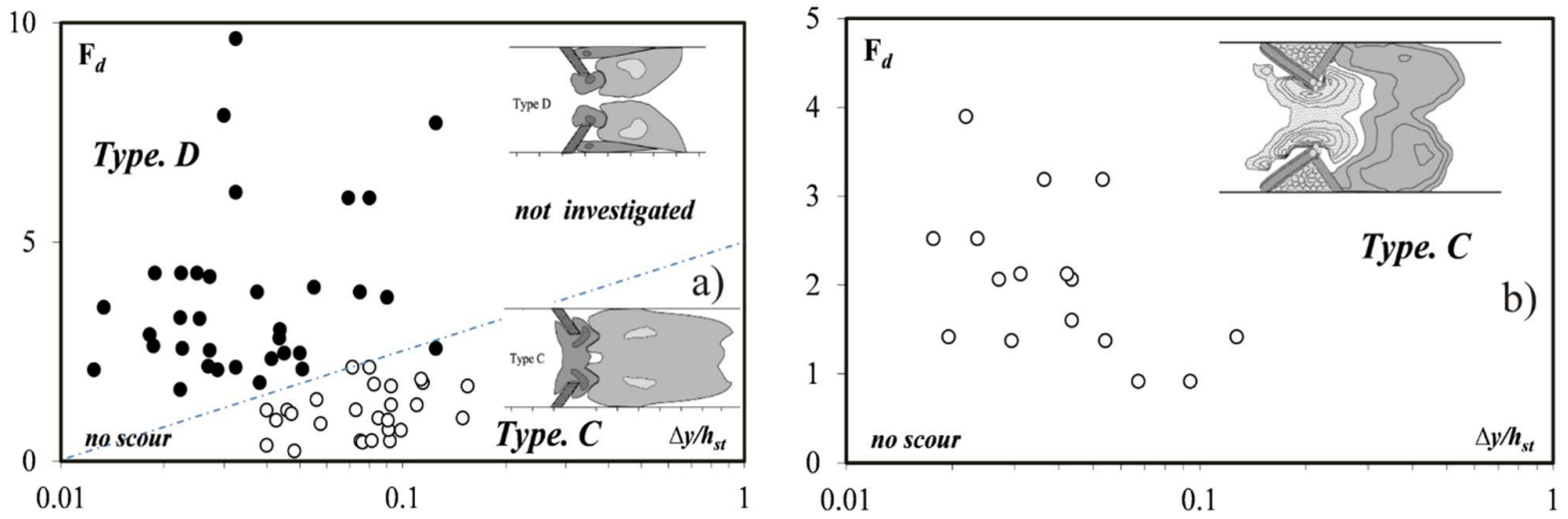

Fig. 11 a) morphology typology for Log-Deflectors (Pagliara et al. 2015) b) occurring just morphology Type C for LogFrame Deflector even for high values of $F_{d}$. 